\title{
Research
}

\section{Patterns of regional variation of opioid prescribing in primary care in England:}

\author{
a retrospective observational study
}

\begin{abstract}
Background

Opioids are a widely prescribed class of drug with potentially harmful short-term and long term side effects. There are concerns about the amounts of these drugs being prescribed in England given that they are increasingly considered ineffective in the context of long term non-cancer pain, which is one of the major reasons for their prescription.
\end{abstract}

\section{Aim}

To assess the amount and type of opioids prescribed in primary care in England, and patterns of regional variation in prescribing.

\section{Design and setting}

Retrospective observational study using publicly available government data from various sources pertaining to opioids prescribed in primary practice in England and Indices of Social Deprivation.

\section{Method}

Official government data were analysed for opioid prescriptions from August 2010 to February 2014. The total amount of opioid prescribed was calculated and standardised to allow for geographical comparisons.

\section{Results}

The total amount of opioid prescribed, in equivalent milligrams of morphine, increased $(r=0.48)$ over the study period. More opioids were prescribed in the north than in the south of England ( $r=0.66, P<0.0001)$, and more opioids were prescribed in areas of greater social deprivation $(r=0.56, P<0.0001)$.

\section{Conclusion}

Long-term opioid prescribing is increasing despite poor efficacy for non-cancer pain potential harm, and incompatibility with best practice. Questions of equality of care arise from higher prescription rates in the north of England and in areas of greater social deprivation. A national registry of patients with high opioid use would improve patient safety for this high-risk demographic, as well as provide more focused epidemiological data regarding patterns of prescribing.

\section{Keywords}

chronic pain; observational study; opioid prescribing; primary care; regional variation; social deprivation.

\section{INTRODUCTION}

Opioid class drugs are potent analgesics that are potentially dangerous and widely used in the treatment of acute pain, cancer pain, and chronic non-cancer pain. ${ }^{1}$ However, there is growing controversy about their use in treating chronic non-cancer pain. ${ }^{2}$ The extent of this use is increasing in the UK, with a substantial impact on patients quality of life, as well as on the economy, both directly and indirectly. ${ }^{3-5}$ Prescribing in primary care is of particular importance given that most long-term prescriptions are initiated in this setting. ${ }^{6}$ Many practitioners routinely prescribe opioids for chronic non-cancer pain because they believe it is unethical to withhold analgesia, regardless of the aetiology of pain, ${ }^{7}$ yet opioids are ineffective in much chronic pain beyond modest effects in the short term. ${ }^{5}$ Further effectiveness of analgesia should be judged not only by pain relief but also by improved function. ${ }^{8}$

Opioid use causes complications and adverse effects,? particularly with longterm use and larger regular doses, such as tolerance; ${ }^{10}$ addiction and abuse; diversion; ${ }^{11}$ hyperalgesia; ${ }^{12}$ gastrointestinal disturbance, immunological dysfunction, hormonal disruption, muscle rigidity, and myoclonus; ${ }^{13}$ raised risk of fracture and acute myocardial infarction in older populations; $i^{14}$ and generally, increased mortality. ${ }^{15}$ Also, dependence makes dose reduction difficult. ${ }^{16}$

L Mordecai, MSc, MRCP, FRCA, pain research fellow, University College London Hospital, London. C Reynolds, MSc, MRCP, respiratory registrar, St Mary's Hospital, London. LJ Donaldson, MSc, MD, FRCP, professor of public health, Faculty of Epidemiology and Public Health, London School of Hygiene and Tropical Medicine, London. AC de $\mathbf{C}$ Williams, PhD, reader, clinical health psychology, Research Department of Clinical, Educational and Health Psychology, University College London, London.

Address for correspondence

Luke Mordecai, the Pain Management Office,
The US has seen an alarming rise in the rate of opioid prescriptions over recent years ${ }^{17}$ deaths involving opioids tripled in the last decade and emergency room visits doubled. ${ }^{18}$ Deaths in England, Scotland, and Wales attributed to opioids have also increased: there were nearly 900 deaths in 2011 compared with almost 500 in $2001 .{ }^{19}$

Several widely prescribed opioids, such as buprenorphine, fentanyl, methadone, morphine, and oxycodone, have no formal upper dose limit. Given the strong association between adverse effects and dose, it is more accurate to describe risk in milligram doses (or dose equivalent) rather than as a count of prescriptions, as in most previous studies.

This study assessed the level and geographical pattern of opioid prescribing in primary care in England over a 3.5 year period, using mg morphine equivalent to express quantity. This provides a national total of England's prescription of opioids overall and its rate of change, as well as regional differences in prescribing. A 2010 government white paper about the $\mathrm{NHS}^{20}$ made a commitment to maximise the value of all health-care-providing services within the NHS, and used atlases of variation across a wide spectrum of clinical specialties ${ }^{21}$ to show unwarranted geographical variation in activity and expenditure. Identifying variation can lead to improvements in clinical and economic outcomes.

3rd floor bridge link, University College Hospital, 235 Euston Road, London, NW1 2BU, UK.

Email: luke.mordecaidgmail.com

Submitted: 19 July 2017; Editor's response: 22 August 2017; final acceptance: 3 November 2017

\section{British Journal of General Practice}

This is the full-length article (published online 13 Feb 2018) of an abridged version published in print. Cite this version as: Br J Gen Pract 2018; DOI: https://doi.org/10.3399/bjgp18X695057 


\section{How this fits in}

It is known that opioid prescriptions are increasing in England, which is a public health issue because of the side effects and the potential for abuse. Additionally many opioids are repeatedly prescribed for contentious reasons. This study confirms this trend, albeit over a short timeframe. It also highlights the large amount of tramadol being prescribed and most importantly reports on the strong relationship that exists between opioids and social deprivation. The latter should be brought to the attention of clinicians and policymakers alike.

Further, although inequalities in the English healthcare system are historically well recognised, with publication of the Black Report in $1980^{22}$ and the Acheson report in $1998,{ }^{23}$ policy has largely failed to narrow the health gap between socioeconomic groups. ${ }^{24}$ Chronic pain affects more of those of lower socioeconomic status ${ }^{4}$ and poor understanding of this complex condition as well as a lack of services may lead to inappropriate prescribing, in this case, of long-term or high doses of opioids. High opioid doses are associated with increased healthcare use, and increased morbidity and mortality. Therefore an examination of regional variation in the prescribing of opioids should be of interest to policymakers from an economic, social equality, and clinical outcomes perspective, and will provide a basis to challenge the primary care system to standardise around best practice and to reduce avoidable harm.

\section{METHOD}

Primary care practice data for opioid prescriptions were obtained from the Health and Social Care Information Centre Inow called NHS Digital; https://digital. nhs.uk/), and information about clinical commissioning groups (CCGs) was provided by the Office for National Statistics (https:// www.ons.gov.uk/). The 209 individual CCGs in England are autonomous bodies responsible for the regional commissioning of most healthcare services.

On the basis of expert opinion regarding the most commonly prescribed opioids, eight opioids were included: buprenorphine, codeine, dihydrocodeine, fentanyl, methadone, morphine, oxycodone, and tramadol, using all available formulations in the British National Formulary (BNF). ${ }^{25}$ The BNF provided data on the monthly total $\mathrm{mg}$ of each drug prescribed in each of the CCGs in England. Because the drugs have different relative potencies, a standardisation calculation was performed, taking a mid-point where a range of values was found in the literature, and confirming the equivalence calculation by expert opinion (full details are available from the authors on request). Adjustment was also made for the size of CCG population using data from the Office for National Statistics. The unit of comparison for opioid prescribing generated is mg morphine equivalent per capita per month per CCG.

To compare regions, geographical latitude was sourced from a mapping website (https://www.distancesfrom.com/), taking the CCG headquarters for the point of latitude. Deprivation was quantified using September 2015 government statistics covering 2012 and 2013 data. ${ }^{26}$ The Index of Multiple Deprivation (IMD) provides statistics combining seven weighted domains: income deprivation (weight $22.5 \%)$; employment deprivation (22.5\%); education, skill, and training deprivation $(13.5 \%)$; health deprivation and disability $(13.5 \%)$; crime (9.3\%); barriers to housing and services (9.3\%); and living environment deprivation (9.3\%).

The opioid dataset comprised 211 CCGs and the IMD dataset 209 (because NHS Gateshead, NHS Newcastle North and East, and NHS Newcastle West were amalgamated into one commissioning body). Opioid totals and populations from these amalgamated CCGs were therefore summed as they pertained to the new larger CCG. Each dataset therefore contained 209 CCGs.

Analysis was performed using the Python pandas data analysis programme. ${ }^{27}$ A Shapiro-Wilk calculation for both the opioid data and the IMD data showed the distributions were non-parametric. Spearman's rank correlation coefficient was used to test for linear correlations between drug prescriptions, region, and social deprivation.

\section{Patient involvement}

Patients Ipeople with chronic pain, particularly those taking opioids) were not involved in setting the research question, selecting outcome measures, developing plans for recruitment, discussing design of the study, or advising on interpretation, writing up, and dissemination of results. Results, once published, will be shared with patient groups and joint patient-professional pain interest groups, encouraging feedback and discussion that may inform further research initiatives. 
Figure 1. Percentage of each opioid prescribed in equivalent $\mathrm{mg}$ morphine in England from August 2010 to February 2014

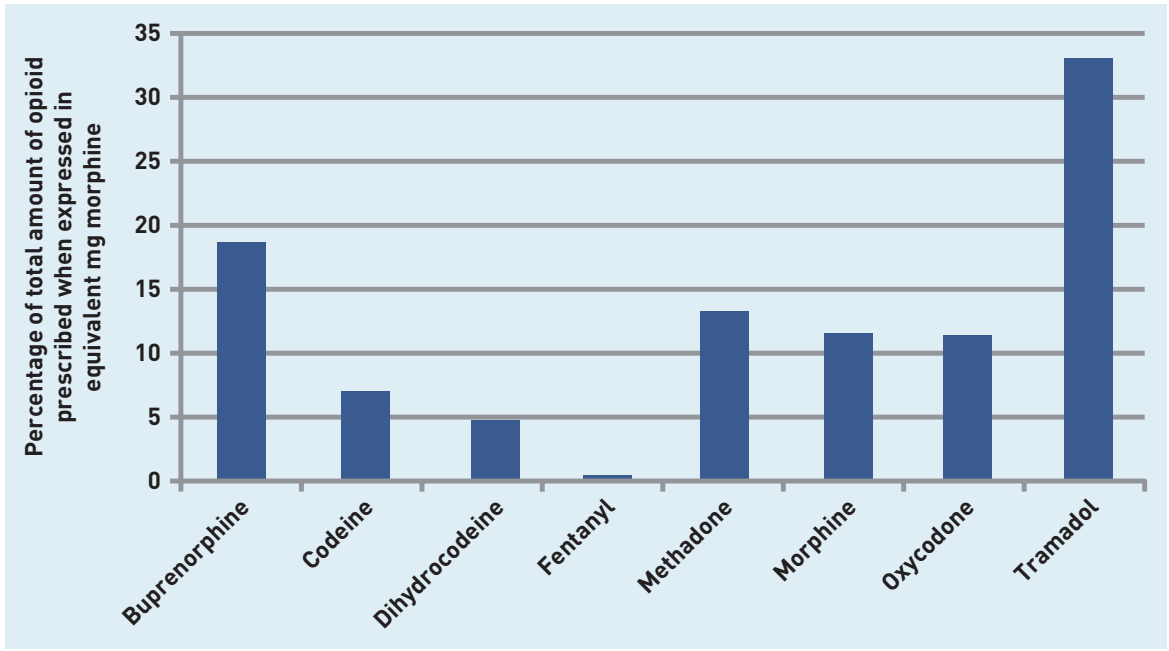

\section{RESULTS}

Figure 1 shows the percentage of each drug prescribed as a proportion of the total mg of morphine equivalent over the entire 43-month study period. Tramadol was the most prescribed, followed by buprenorphine and methadone. Fentanyl was, by far, the least prescribed drug. The mg morphine equivalent of each drug, and change over time, are shown in Table 1. Buprenorphine and codeine showed the greatest rate of increase over the study period $(r \geq 0.86)$, whereas only two opioids, methadone and dihydrocodeine, showed a decrease. (Full details of monthly data on each drug are available from the authors on request.)

Figure 2 shows the increase in the morphine equivalent of all eight opioids combined prescribed over the study period $(r=0.48)$. Geographical variation is evident, with the highest (red) and lowest (light blue) rates of opioid prescription clearly demonstrated in Figure 3. Almost all of the low prescribing areas were in the south of England and nine of the ten highest prescribing areas were northern CCGs; Bristol is the only southern CCG in the ten. Substantial correlations emerged between the amount of opioid prescribed and more northerly latitude of CCGs $(r=0.66$, $P<0.0001$ ) (Figure 4), representing 44\% shared variance.

Comparison of prescribing rates with Index of Social Deprivation also showed a strong relationship $(r=0.56, P<0.0001)$ (Figure 5), representing $31 \%$ shared variance. When latitude was included as a covariate, this correlation was stronger ( $r=0.43$, two-tailed, $P<0.001)$.

\section{DISCUSSION}

\section{Summary}

In this study of opioid medication prescribed by primary care services in England, volume and pattern of use, in $\mathrm{mg}$, of eight opioid drugs and their total morphine equivalent

Table 1. Absolute amount and mean grams of each opioid prescribed
over the study period, and the linear correlation between monthly over the study
total and time

\begin{tabular}{lccc} 
Opioid & $\begin{array}{c}\text { Total amount } \\
\text { prescribed over } \\
\text { study period, }\end{array}$ & $\begin{array}{c}\text { Mean } \mathbf{g} \text { /month } \\
\text { prescribed in } \\
\text { England }\end{array}$ & $\begin{array}{c}\text { Increase or } \\
\text { decrease over time } \\
\text { [Spearman's } \boldsymbol{r} \text { ) }\end{array}$ \\
\hline Buprenophine & 92500.3 & 2151.2 & 0.86 \\
\hline Codeine & 27922622.7 & 649363.3 & 0.89 \\
\hline Dihydrocodeine & 22190184.3 & 516050.8 & -0.27 \\
\hline Fentanyl & 2489.5 & 57.9 & 0.18 \\
\hline Methadone & 1931295.7 & 44913.8 & -0.97 \\
\hline Morphine & 4835679.9 & 112457.7 & 0.75 \\
\hline Oxycodone & 2719720.2 & 63249.3 & 0.86 \\
\hline Tramadol & 139222060.4 & 3237722.3 & 0.80 \\
\hline
\end{tabular}




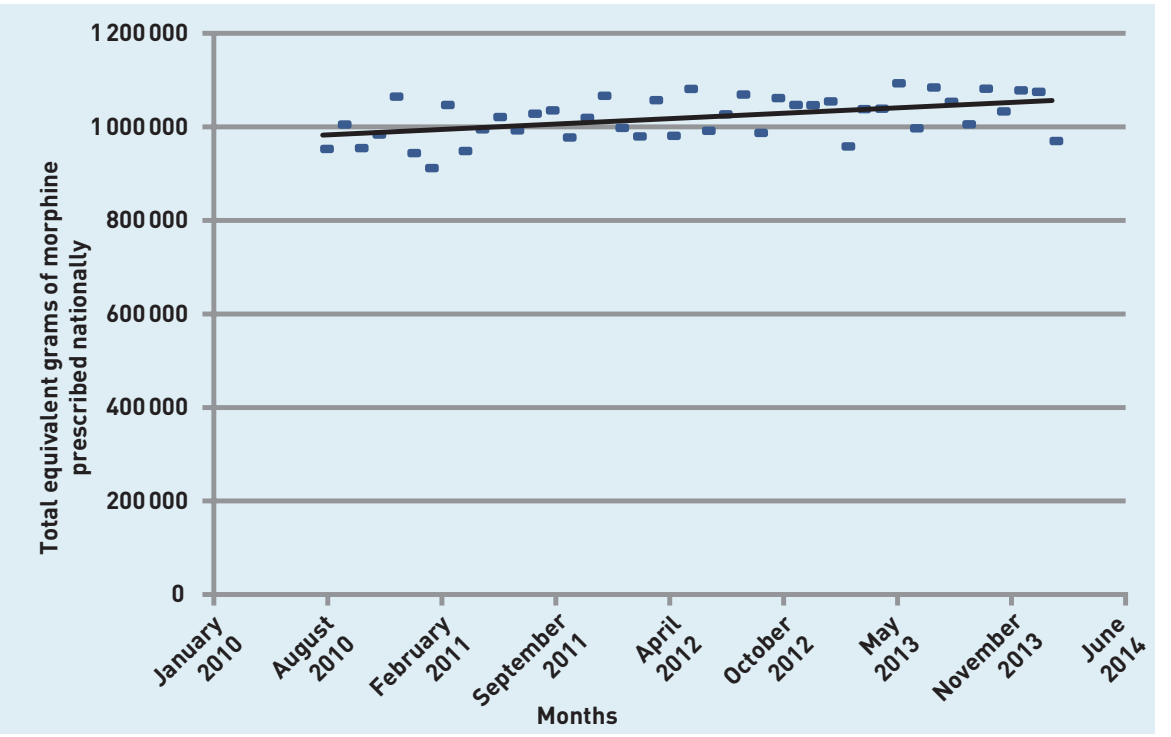

Figure 2. Total opioids prescribed in equivalent grams of morphine in England per month from August 2010 to February $2014\left(\mathrm{r}=0.48, \mathrm{r}^{2}=0.23\right)$.

Figure 3. Variation in English CCGs in opioid prescribing in equivalent mg of morphine from August 2010 to February 2014. $C C G$ = clinical commissioning group.

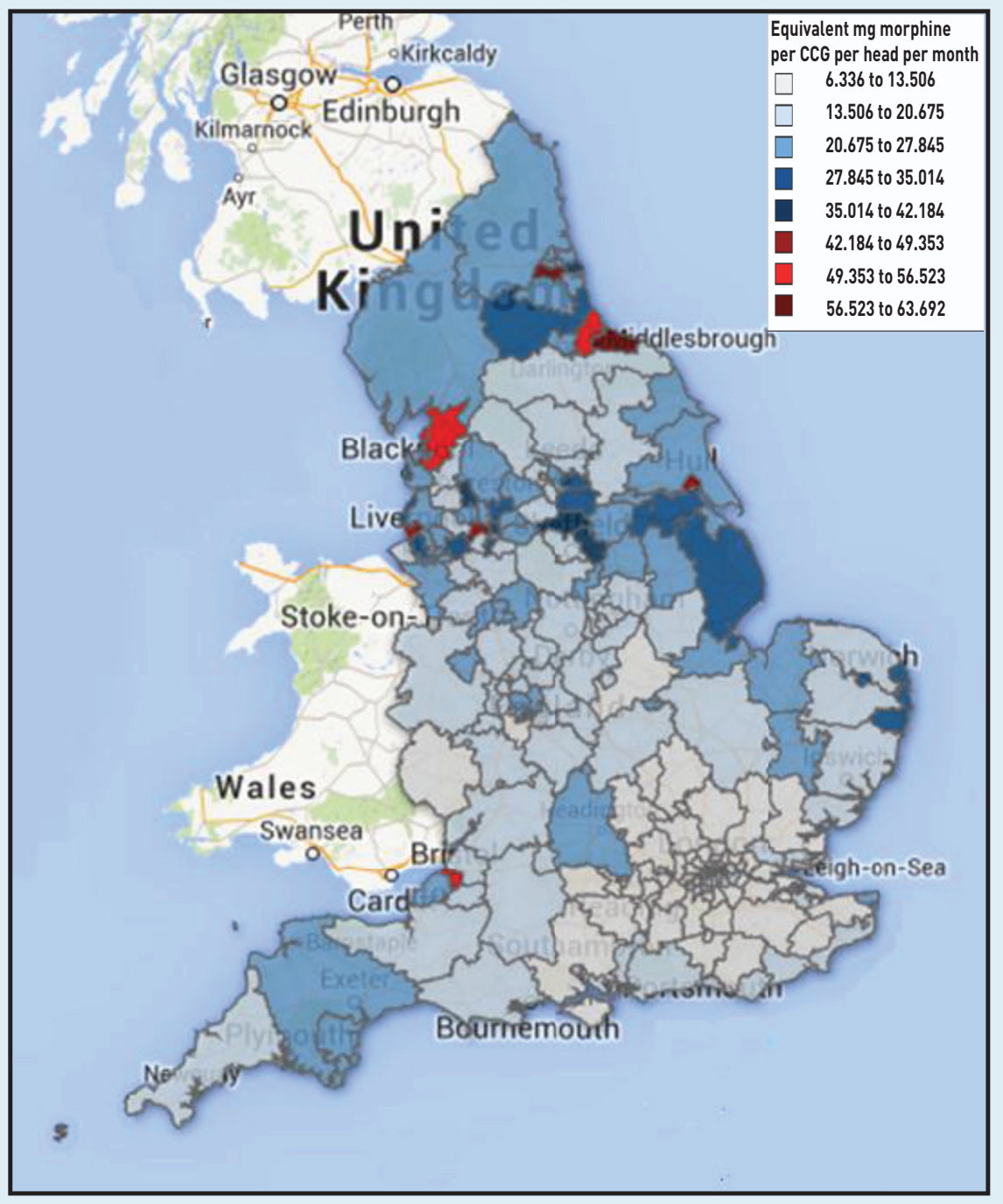

were evaluated. Over the 43-month study, an overall increase in opioid prescribing was found, specifically of buprenorphine, codeine, morphine, oxycodone, and tramadol, which was the most prescribed opioid in England. A north-south gradient in opioid usage was also found, with nine out of ten of the highest prescribing areas located in the north of the country, and there was an association between social deprivation and higher opioid prescription.

Different drugs showed different patterns of change that may cast light on differences in prescription rates. There are several possible reasons for the increase in tramadol prescriptions. First, it fills a potential void left after withdrawal in the mid-2000s of co-proxamol because of adverse effects; tramadol is perceived to be equipotent. Second, tramadol is prescribed in preference to non-steroidal anti-inflammatory drugs because of concerns over complications, especially in older people. ${ }^{28}$ Third, the drug may be perceived, in therapeutic terms, to lie between weak and strong opioids lan unhelpful distinction because it depends on dose), ${ }^{29}$ providing a false sense of security to prescribers hoping to avoid the stigma and risks of 'strong' opioids. The increase in tramadol prescriptions raises public health concerns: for example, tramadol-related deaths from all drug misuse in Northern Ireland increased from $9 \%$ in 2001 to $40 \%$ in 2011,30 and in England it was responsible for 132 deaths in 2010 rising to 240 in $2014 .{ }^{31}$ In 2014 UK legislation reclassified tramadol as a schedule 3 controlled drug and prohibited prescription of more than a month's supply at any one time; ${ }^{32}$ this may reduce prescription rates and fatalities associated with use. Rescheduling of codeine in Australia in 2010 has, however, failed to have any effect, ${ }^{33}$ so the intended benefits of the English legislation are not guaranteed.

Codeine and dihydrocodeine are closely related, and are the two least potent analgesics in this study. Both are widely prescribed for acute pain, especially that linked to outpatient procedures and minor trauma; they are also used to treat diarrhoea in patients with intestinal failure. ${ }^{34}$ Although the absolute amounts prescribed were of the same order of magnitude, prescriptions of codeine increased faster than all other opioids in this study, with dihydrocodeine prescriptions decreasing the most. The likely explanations for the increase in codeine prescriptions are similar to those for tramadol, although it is difficult to explain why dihydrocodeine prescribing decreased. Although codeine and dihydrocodeine are 


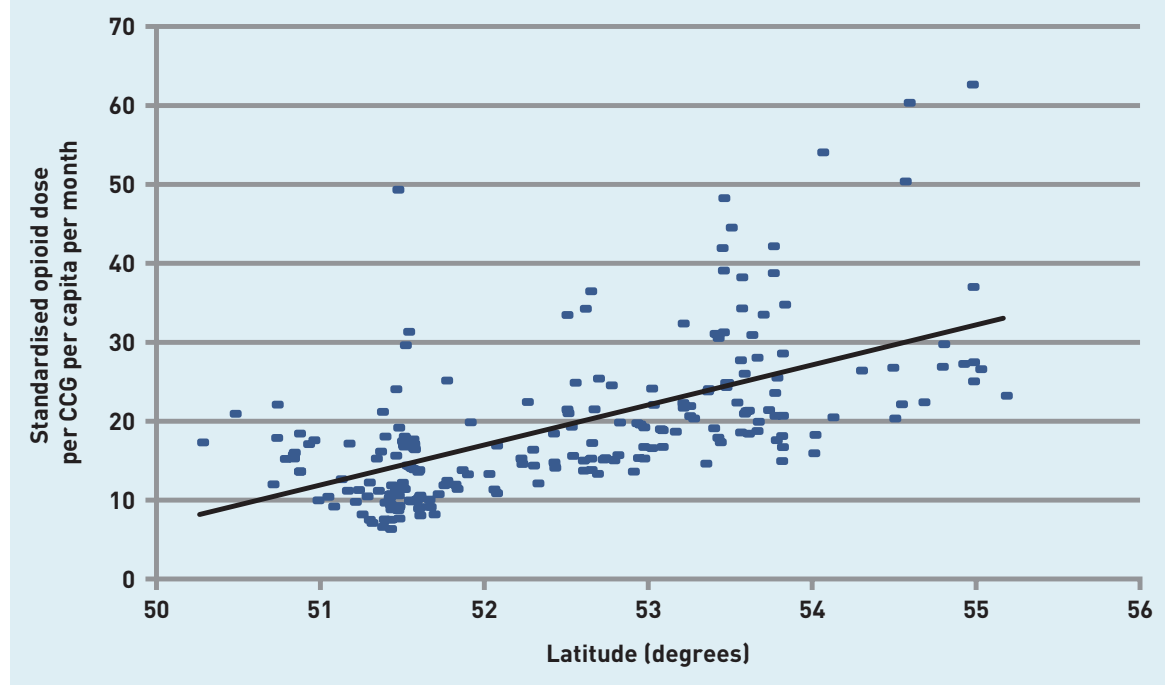

Figure 4. Relationship between amount of opioid prescribed, in equivalent mg morphine, and latitude of clinical commissioning group $\left(\mathrm{r}^{2}=0.36\right) . c C G=$ clinical commissioning group.

Figure 5. Relationship between the amount of opioid prescribed, in equivalent mg morphine, and social deprivation index of CCGs from August 2010 to February $2014\left(\mathrm{r}^{2}=0.28\right)$. CCG = clinical commissioning group. often described as weak opioids, they still carry risks. In England, deaths related to codeine increased from 73 in 2012 to 130 in 2013. Dihydrocodeine accounted for 103 and 102 deaths over the same years, with codeine and dihydrocodeine cumulatively accounting for over $12 \%$ of opioid-related deaths in England in 2013. ${ }^{31}$

Morphine and oxycodone are both strong analgesics with approximately equal potency. The monthly totals of morphine prescribed nationally demonstrated noticeable variation within the overall increase, but with no obvious pattern. The adverse effect profile of morphine includes pruritus, sedation, and, most commonly, constipation, and oxycodone is often used as a second-line drug for affected patients. Additionally, oxycodone is now available in a combined oral formulation with naloxone, proven to reduce constipation. ${ }^{35}$ The

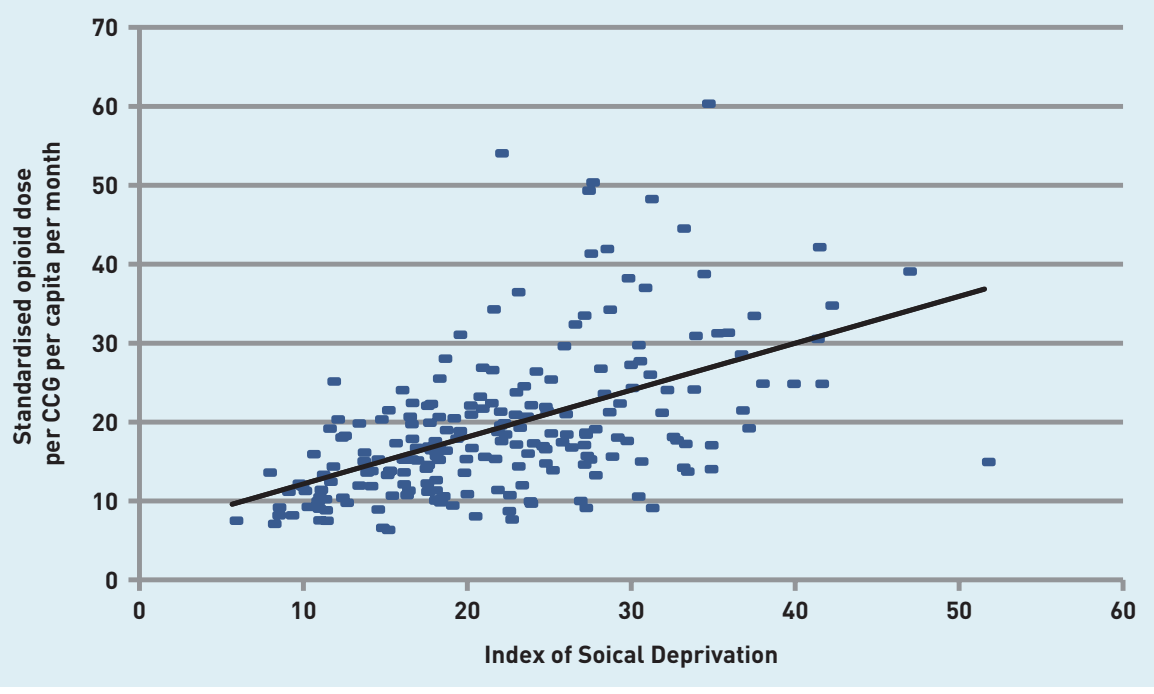

combination of standard oxycodone recently coming off patent, rendering it cheaper, and the utility of oxycodone/naloxone, despite its expense, are likely explanations for the increasing trend in oxycodone prescriptions.

The amount of methadone prescribed, most of which is used to treat drug dependency rather than pain, decreased over the period. This may be related to the simultaneous rise in buprenorphine prescription, because a high-dose oral formulation of buprenorphine can be used as an alternative to methadone in the treatment of opioid dependence. ${ }^{36}$ Buprenorphine acts both as a partial agonist and antagonist at different endogenous opioid receptors, producing fewer undesirable effects of hypotension, respiratory depression, and sedation and euphoria, ${ }^{37}$ thus some consider it a safer option for treating opioid addiction.

Fentanyl is the least prescribed drug and the quantities prescribed remained largely constant over the study period. The absence of a tablet preparation, its high potency, and quick onset and offset mean that treatment is less likely to be initiated in primary care, despite the increasing popularity of transdermal preparations.

\section{Strengths and limitations}

This study used data sources that cover the entire country and expresses the total amount of drug prescribed in terms of equivalent $\mathrm{mg}$ of morphine, which is quantitatively more informative than the number of prescriptions metric used in many other studies.

Opioids are prescribed for one of three main reasons: controversially for chronic pain, conventionally for pain associated with end-of-life conditions, and briefly for acute pain. Data were not available to identify prescriptions for chronic pain alone. It would be very valuable to have information on these reasons for prescription, and, even more so, some demographic information on the prescription recipient. These could, at least, be addressed in small-scale data collection.

The study methodology inevitably underestimated the amount of opioids prescribed in the study period. First, the opioids included were not all the opioids available on prescription: lesser-prescribed drugs, such as diamorphine, pethidine, and the recently licensed tapentadol, were excluded. However, the eight opioids reported account for most opioids prescribed nationally. Second, opioid prescriptions were expressed as mg of morphine equivalent; there is no universally agreed method for 
this calculation, but different equivalence indices would not affect relative changes in rates of prescription per opioid, nor the associations with geographical region and social deprivation. Third, specifically relating to codeine, over-the-counter use is not included in prescribing data, and, although this form of codeine is a weak preparation, the inclusion of this drug in the study is justified because of its adverse effects and abuse profiles, as well as the risk that it is a gateway to stronger analgesics. ${ }^{38}$ This study cannot provide a definitive analysis of trends in opioid prescribing because the study period was too short. However, the direction of change over the 43 months is consistent with other studies. The records of prescriptions used for this study began in August 2010, so further historical data to support longer-term trend analysis were not available; as more data accumulate, reliable assessment of trends will be important.

\section{Comparison with existing literature}

The US accounts for 5\% of the world's population and $80 \%$ of global opioid use..$^{39}$ This astonishing yet widely publicised consumption probably explains why the US often features as the international reference point. However, given the significant differences between the English and American healthcare systems, a more appropriate comparator should perhaps be sought. A study of opioid consumption in the five Nordic countries between 2002 and 2006, in terms of defined daily doses per 1000 inhabitants per day, showed that each country prescribed very different amounts of each opioid and that the overall amount increased in all countries except Sweden. ${ }^{40}$ Oxycodone showed the most rapid increase in prescriptions. Because data are presented graphically and in different units to this study, no quantitative comparisons can be made. Sweden's reduction in overall consumption was attributable to fewer prescriptions of weak opioids; the authors suggested that changes could be due to marketing, availability, reimbursement, prescription policies, or national and international guidelines. ${ }^{40}$ How should regional variation in prescribing be best understood? Because there is no significant regional variation in rates of chronic pain ${ }^{4}$ or cancer, ${ }^{42}$ neither should account for regional differences in opioid prescription. Furthermore, it is known from a study in 2014 that only $12.2 \%$ of the prescriptions for strong opioids in England are written for cancer pain, implying that most are supplied for potentially more contentious uses, as outlined in the introduction. ${ }^{43}$ The total opioids prescribed in a given region do not provide any information on the appropriateness of the prescriptions, nor whether prescriptions were filled and the opioids taken by patients at all or as prescribed. Nor can the suitability of the dose prescribed be identified, or whether the prescription was initiated in specialist care; the British Pain Society recommends specialist pain clinic supervision for those prescribed the equivalent of more than 120 mg morphine a day. ${ }^{44}$

The strong relationship found between Indices of Social Deprivation and opioids prescribed is likely to be at least in part attributable to the higher prevalence of chronic pain in people of lower socioeconomic status. In 2011, $40 \%$ of males and $44 \%$ of females in the lowest income quartile met the criteria for chronic pain (British Pain Society definition), compared with $24 \%$ and $30 \%$, respectively, in the highest quartile. ${ }^{4}$ Additionally, there is a strong association between unemployment and poor outcomes in chronic pain.45.46 A 2016 article from Norway, a comparable country in terms of development and health system, corroborated the link between long-term analgesic use and lower socioeconomic status; long-term analgesic use was also associated with being female, older, and less physically active, although prescriptions were counted rather than amount of drug prescribed. ${ }^{47}$ Multiple studies have shown that the best long-term outcomes, in terms of quality of life and functionality, for patients with chronic pain emanate from treatment by a specialist multidisciplinary team. ${ }^{48-50}$ These multidisciplinary programmes rely on taught self-management techniques but are a scarce and expensive resource that are available only to a small proportion of those with long-term pain. ${ }^{51}$ Data extrapolated from the National Pain Audit would suggest that there is no link between access to specialist services and opioid prescriptions, ${ }^{51}$ but, given the relatively small proportion of patients treated in specialist pain services each year and some incomplete data in a very complex audit, robust conclusions cannot be drawn. Furthermore, comparisons with National Pain Audit data were rendered even more difficult by the change of governance boundaries in England in 2012 from primary care trusts (used in the National Pain Audit) to CCGs.

A study carried out in the US in 2008 used a large sample of different opioid prescriptions to calculate the total amount of opioid prescribed in a similar manner to that used in this study. The authors 
reported a four-fold regional variation between the 25th and 75th centiles of lowest and highest prescribing areas nationwide. ${ }^{52}$ Higher prescription rates in the US were most strongly correlated with a greater density of physicians, and with higher proportions of white non-Hispanic or African American poor people, and people who were uninsured and living in urban areas. ${ }^{52}$ Variations in the data in the current study are attributable to factors beyond patient characteristics, health, or insurance status; ${ }^{53}$ some variation due to chance is inevitable and expected, ${ }^{54}$ and indeed one study has suggested that up to $75 \%$ of the variation cannot be accounted for because of causality as yet undiscovered or indeed just as a natural phenomenon. ${ }^{55}$ Both the current study and the US study demonstrated geographical differences in opioid prescribing, despite substantial differences in the two healthcare systems, particularly in the forces governing supply and demand. In the US study, the largest single cause of higher prescription numbers was the number of active clinicians, whereas, in England, low opioid prescription rates were evident in areas with the highest and lowest concentrations of GPs: the South West (71.3 per 100000 population) and the East (63 per 100000 population). 56

This study demonstrates an association between increased opioid prescribing and lower socioeconomic status, for reasons that require further investigation. One study from Australia found that older populations, people from lower socioeconomic backgrounds, and those with an uncertain prognosis were less likely to question medical advice. ${ }^{57}$ Given that all three of these characteristics often apply to people with chronic pain, ${ }^{4}$ these patients may be less likely to request referral to specialist services and rehabilitation, or to question the prescription of opioids from their primary care provider. These hypotheses are testable and might cast much-needed light on this subject.

\section{Implications for research and practice}

This study exposes increasing rates of prescription of a class of drugs whose use for chronic pain is controversial, with potential for abuse, and an association with serious adverse effects and premature death. ${ }^{58}$ The authors call on policymakers to identify the reasons for this variation to enable avoidable harm to be addressed.

The specialist pain service infrastructure lacks capacity: data extrapolated from the 2010-2012 National Pain Audit suggests that as few as one in five people with problematic pain has access to specialist pain services, and that only $40 \%$ of those services offer best practice in the form of multidisciplinary team assessment and treatment. ${ }^{51}$ The profile of chronic pain has been raised substantially in the last few years and good practice needs now to extend from specialist to primary care. The British Pain Society and Map of Medicine have produced a series of guidelines aimed at standardising care for the most common types of chronic pain, using evidence-based algorithms. ${ }^{59}$ If the treatment of chronic pain in the community followed these, opioid prescription would be likely to fall and the function of those with chronic pain to improve.

Finally, the authors would recommend the institution of a national database of patients taking large amounts of opioids. As discussed, this is a high-risk demographic, which should be known to and regularly followed up by specialist services. This would hopefully help avoid further escalations of doses as well as attempt to help patients with specialist opioid reduction programmes. Furthermore, the epidemiological data collected might help shed further light on a confusing distribution of high opioid use and target areas for future research.

\section{Funding}

None.

\section{Provenance}

Freely submitted; externally peer reviewed.

\section{Competing interests}

The authors have declared no competing interests.

\section{Discuss this article}

Contribute and read comments about this article: bjgp.org/letters 


\section{REFERENCES}

1. Pasternak GW, ed. The opiate receptors. 2nd edn. New York, NY: Humana Press/Springer, 2011.

2. Noble M, Treadwell JR, Tregear SJ, et al. Long-term opioid management for chronic noncancer pain. Cochrane Database Syst Rev2010; (1): CD006605. DOI: 10.1002/14651858.CD006605.pub2.

3. Chief Medical Officer. 150 years of the annual report of the Chief Medical Officer: on the state of public health. London: Department of Health, 2008.

4. Health and Social Care Information Centre. Health survey for England 2011. Leeds: HSCIC, 2012

5. Kalso E, Edwards JE, Moore RA, McQuay HJ. Opioids in chronic non-cancer pain: systematic review of efficacy and safety. Pain 2004; 112(3): 372-380.

6. Clarke H, Soneji N, Ko DT, et al. Rates and risk factors for prolonged opioid use after major surgery: population based cohort study. BMJ 2014; 348: g1251.

7. Edlund MJ, Steffick D, Hudson T, et al. Risk factors for clinically recognized opioid abuse and dependence among veterans using opioids for chronic noncancer pain. Pain 2007; 129(3): 355-362.

8. Højsted J, Sjøgren P. An update on the role of opioids in the management of chronic pain of nonmalignant origin. Curr Opin Anaesthesiol 2007; 20(5): 451-455.

9. Baldini A, Von Korff M, Lin EH. A review of potential adverse effects of longterm opioid therapy: a practitioner's guide. Prim Care Companion CNS Disord 2012; 14(3): PCC.11m01326.

10. Chang G, Chen L, Mao J. Opioid tolerance and hyperalgesia. Med Clin North Am 2007; 91(2): 199-211.

11. Ballantyne JC, LaForge KS. Opioid dependence and addiction during opioid treatment of chronic pain. Pain 2007; 129(3): 235-255.

12. Ossipov MH, Lai J, King T, et al. Underlying mechanisms of pronociceptive consequences of prolonged morphine exposure. Biopolymers 2005; 80(2-3): 319-324.

13. Benyamin R, Trescot AM, Datta S, et al. Opioid complications and side effects. Pain Physician 2008; 11(2 Suppl): S105-S120.

14. Ballantyne JC. 'Safe and effective when used as directed': the case of chronic use of opioid analgesics. J Med Toxicol 2012; 8(4): 417-423.

15. Solomon DH, Rassen JA, Glynn RJ, et al. The comparative safety of opioids for nonmalignant pain in older adults. Arch Intern Med 2010; 170(22): 1979-1986.

16. Ballantyne JC, Shin NS. Efficacy of opioids for chronic pain: a review of the evidence. Clin J Pain 2008; 24(6): 469-478.

17. Meldrum ML. The ongoing opioid prescription epidemic: historical context Am J Public Health 2016; 106(8): 1365-1366.

18. Fields HL. The doctor's dilemma: opiate analgesics and chronic pain. Neuron 2011; 69(4): 591-594.

19. Giraudon I, Lowitz K, Dargan Pl, et al. Prescription opioid abuse in the UK. $\mathrm{Br}$ $J$ Clin Pharmacol 2013; 76(5): 823-824.

20. Department of Health. Liberating the NHS. London: The Stationery Office, 2010

21. Public Health England. Tackling unwarranted variation in healthcare across the NHS. London: Public Health England, 2015

22. Socialist Health Association. Black Report 6 explanation of health inequalities. 1980. http://www.sochealth.co.uk/resources/public-health-and-wellbeing/ poverty-and-inequality/the-black-report-1980/black-report-6-explanation-ofhealth-inequalities/ (accessed 29 Jan 2018).

23. Acheson D. Independent inquiry into inequalities in health report. The Stationery Office, 1998. http://www.gov.uk/government/publications/ independent-inquiry-into-inequalities-in-health-report laccessed 29 Jan 2018).

24. Earwicker R. Progress in tackling health inequalities: a policy maker's reflections. In: Dowler E, Spencer N, eds. Challenging health inequalities. From Acheson to 'Choosing health'. Bristol: Policy Press, 2007: 17-30.

25. Joint Formulary Committee. British national formulary. 73rd edn. London: BMJ Group and Pharmaceutical Press, 2017.

26. Department for Communities and Local Government. The English Indices of Deprivation 2015. https://www.gov.uk/government/statistics/english-indicesof-deprivation-2015 (accessed 20 Nov 2017).

27. Reynolds C. Opiate prescribing in England. Jupyter nbviewer, 2015. http://nbviewer.ipython.org/urls/gist. githubusercontent.com/drcjar/81e02f933943f3a297f6/
raw/804a6ab6f33bdde355c7a007612c87b77025852c/OpiateAnalysis.ipynb laccessed 29 Jan 2018).

28. Harirforoosh S, Asghar W, Jamali F. Adverse effects of nonsteroidal antiinflammatory drugs: an update of gastrointestinal, cardiovascular and renal complications. J Pharm Pharm Sci 2013; 16(5): 821-847.

29. [No authors listed]. Strong opioids for osteoarthritis in primary care? Drug Ther Bull 2009; 47(12): 138-141.

30. Randall C, Crane J. Tramadol deaths in Northern Ireland: a review of cases from 1996 to 2012. J Forensic Leg Med 2014; 23: 32-36.

31. Office for National Statistics. Deaths related to drug poisoning in England and Wales: 2014 registrations. London: Office for National Statistics, 2015.

32. Amendments to the misuse of drugs regulations 2001. http://www.legislation. gov.uk/uksi/2014/1275/regulation/5/made (accessed 20 Nov 2017).

33. Cairns R, Brown JA, Buckley NA. The impact of codeine re-scheduling on misuse: a retrospective review of calls to Australia's largest poisons centre. Addiction 2016; 111(10): 1848-1853.

34. Arebi N, Forbes A. High-output fistula. Clin Colon Rectal Surg 2004; 17(2): 89-98.

35. Power I. An update on analgesics. Br J Anaesth 2011; 107(1): 19-24.

36. Schuckit MA. Treatment of opioid-use disorders. N Engl J Med 2016; 375(4): 357-368.

37. Reed LJ, Glasper A, de Wet CJ, et al. Comparison of buprenorphine and methadone in the treatment of opiate withdrawal: possible advantages of buprenorphine for the treatment of opiate-benzodiazepine codependent patients? J Clin Psychopharmacol 2007; 27(2): 188-192.

38. Zamparutti G, Schifano F, Corkery JM, et al. Deaths of opiate/opioid misusers involving dihydrocodeine, UK, 1997-2007. Br J Clin Pharmacol 2011; 72(2): 330-337.

39. Knaggs RD, Stannard C. Opioid prescribing: balancing overconsumption and undersupply. Br J Pain 2017; 11(1): 5

40. Hamunen K, Paakkari P, Kalso E. Trends in opioid consumption in the Nordic countries 2002-2006. Eur J Pain 2009; 13(9): 954-962.

41. Bridges S. Chronic pain. In: NHS Digital. Health survey for England - 2011, health, social care and lifestyles. 2012. http://digital.nhs.uk/catalogue/ PUB09300 (accessed 29 Jan 2018)

42. Office for National Statistics. Cancer atlas of the United Kingdom and Ireland 1991-2000. London: Palgrave Macmillan, 2005

43. Zin CS, Chen LC, Knaggs RD. Changes in trends and pattern of strong opioid prescribing in primary care. Eur J Pain 2014; 18(9): 1343-1351.

44. Faculty of Pain Medicine. Opioids aware: a resource for patients and healthcare professionals to support prescribing of opioid medicines for pain. http://www.fpm.ac.uk/faculty-of-pain-medicine/opioids-aware laccessed 20 Nov 2017).

45. Grotle M, Foster NE, Dunn KM, Croft P. Are prognostic indicators for poor outcome different for acute and chronic low back pain consulters in primary care? Pain 2010; 151(3): 790-797.

46. Dunn KM, Jordan KP, Croft PR. Contributions of prognostic factors for poor outcome in primary care low back pain patients. Eur J Pain 2011; 15(3): 313-319.

47. Samuelsen PJ, Svendsen K, Wilsgaard T, et al. Persistent analgesic use and the association with chronic pain and other risk factors in the population: a longitudinal study from the Troms $\varnothing$ Study and the Norwegian Prescription Database. Eur J Clin Pharmacol 2016; 72(8): 977-985.

48. Rasmussen C, Nielsen GL, Hansen VK, et al. Rates of lumbar disc surgery before and after implementation of multidisciplinary nonsurgical spine clinics. Spine 2005; 30(21): 2469-2473.

49. Guzmán J, Esmail R, Karjalainen K et al. Multidisciplinary bio-psycho-social rehabilitation for chronic low back pain. Cochrane Database Syst Rev 2002; (1): CD000963.

50. Flor H, Fydrich T, Turk DC. Efficacy of multidisciplinary pain treatment centers: a meta-analytic review. Pain 1992; 49(2): 221-230.

51. British Pain Society. National pain audit final report 2010-2012. London: British Pain Society, 2012. https://www.britishpainsociety.org/static/uploads/ resources/files/members_articles_npa_2012_1.pdf (accessed 29 Jan 2018).

52. McDonald DC, Carlson K, Izrael D. Geographic variation in opioid prescribing in the U.S. J Pain 2012; 13(10): 988-996.

53. Zhang Y, Baicker K, Newhouse JP. Geographic variation in Medicare drug spending. N Engl J Med 2010; 363(5): 405-409. 
54. Diehr $\mathrm{P}$, Cain $\mathrm{K}$, Connell F, Volinn E. What is too much variation? The null hypothesis in small-area analysis. Health Serv Res 1990; 24(6): 741-771.

55. Congressional Budget Office. Geographic variation in health care spending. 2008. https://www.cbo.gov/publication/41669 (accessed 20 Nov 2017).

56. NHS Digital. General and personal medical services, England - 2002-2012. http://content.digital.nhs.uk/catalogue/PUB09536/nhs-staf-2002-2012-geneprac-rep.pdf laccessed 20 Nov 2017).

57. Meyer SB, Ward PR, Jiwa M. Does prognosis and socioeconomic status impact on trust in physicians? Interviews with patients with coronary disease in South Australia. BMJ Open 2012; 2: e001389.

58. Paulozzi LJ. Opioid analgesic involvement in drug abuse deaths in American metropolitan areas. Am J Public Health 2006; 96(10): 1755-1757.

59. British Pain Society. Guidelines for pain management programmes for adults: an evidence-based review prepared on behalf of the British Pain Society. London: British Pain Society, 2013. https://www.britishpainsociety.org/static/ uploads/resources/files/pmp2013 main FINAL v6.pdf laccessed 29 Jan 2018). 